\title{
Drastically elevated levels of Interleukin-6 and its soluble receptor complex in COVID-19 patients with acute respiratory distress
}

\author{
Gaetano Di Spigna $^{1 \#}$, Daniela Spalletti Cernia ${ }^{1 \#}$, Maria Vargas ${ }^{2}$, Luigi Buonavolontà ${ }^{1}$, Giuseppe Servillo ${ }^{2}$ and Loredana Postiglione $^{1,3 *}$ \\ ${ }^{1}$ Department of Translational Medical Sciences, University of Naples "Federico II", Naples, Italy \\ ${ }^{2}$ Department of Neurosciences, Reproductive Sciences and Odontostomatology, University of Naples "Federico II", Naples, Italy \\ ${ }^{3}$ Center for Basic and Clinical Immunology Research (CISI), University of Naples "Federico II", Naples, Italy \\ \#Both authors contributed equally
}

\begin{abstract}
In December 2019 a novel RNA beta-corona virus, highly contagious, was recognized to be the cause of previously pneumonia cases of unknown origin. The virus is phylo-genetically similar to SARS-CoV and has been called SARS-CoV-2 (COVID-19). Most common is the emerging of a strong dys-regulation of the immune response, that leads to disease severity in COVID-19 patients.

There are a lot of suggestions indicating that mortality, strong in critically ill patients, might be correlated with virally driven hyper-inflammation, due to a cytokine storm. Interleukin-6 (IL-6) plays an important role in cytokine release syndrome and elevated IL-6 level is a hallmark inflammatory signature seen in serum of patients with severe COVID-19 acute respiratory distress (ARDS).

We analyzed blood inflammation indicators, IL- 6 and its receptor complex and TNF- $\alpha$, in order to demonstrate that cytokines unbalanced systems can be considered an early tool to identify critical patients and to predict their poor prognosis.

Our study was conducted on $\mathrm{N}=23$ critically patients with confirmed COVID-19 and admitted in Intensive Care Unit (ICU) from March 10 to April 30 due to severe respiratory failure.

Serum levels of IL-6, sIL-6R, sgp130 and TNF- $\alpha$ were determined using CLIA and ELISA as immunoassay.

Our data shown that not all patients have higher values in serum of sIL-6R agonist receptor, compared to the controls. For this reason we have stratified all patients in two different group (1 and 2).

We observed that in GROUP 1 as well as in GROUP 2 the IL-6 and TNF- $\alpha$ serum levels are significantly increased in respect to the controls. Despite, sgp130 antagonist receptor levels are significantly decreased in all patients.

Further studies are required to better investigate the role of IL-6 and its soluble receptor complex during COVID-19 disease and to evaluate the possible involvement of other cytokines also in response to different pharmacological treatment.
\end{abstract}

\section{Introduction}

Several patients with profound inflammatory response associated with the pneumonitis appeared, in December 2019, in the epicenters of infection in Wuhan, China, Northern Italy and in USA (the Seattle and New York City areas), and a viral pneumonia currently sweeping the world was in the process of development [1]. Several days later, the highly contagious virus was identified as a new Beta-Coronavirus, which was officially named Severe Acute Respiratory SyndromeCoronavirus 2 (SARS-CoV-2). The disease caused by SARS-CoV-2 has been named Coronavirus Disease 2019 (COVID-19) responsible for the recent pandemic. To date, COVID-19 has already affected numerous (7,82 millions) people globally, with a $18 \%$ mortality rate [2].

Although most cases were mild to moderate, some patients developed severe symptoms characterized by respiratory dysfunction and/or multiple organ failure.
The virus then activates the innate and adaptive immune system, resulting in the release of a large number of cytokines; in fact it has been suggested that one of the possible mechanisms underlying rapid disease progression is a "cytokine storm". Previous retrospective studies indicated that an elevated level of Interleukin-6 (IL-6) was associated with high case fatality in COVID-19 patients [3].

IL-6 is a polyfunctional cytokine that regulates a very large number of cellular activities. IL-6 is one of major immune-modulatory

${ }^{\star}$ Correspondence to: Loredana Postiglione, Department of Translational Medical Sciences, Center for Basic and Clinical Immunology Research (CISI), University of Naples "Federico II", Naples, Italy, Tel: +39 817463016; E-mail: loredana. postiglione@unina.it

Key words: acute respiratory distress, COVID-19, cytokine storm, IL-6 and soluble receptor complex, TNF- $\alpha$

Received: July 13, 2020; Accepted: July 21, 2020; Published: July 27, 2020 
agent, playing active roles in the regulation of acute phase reactions, activation of $\mathrm{T}$ helper cells, inhibition of T regulatory (Tregs) cells and differentiation of $\mathrm{B}$ cells by orchestrating innate and adaptive immune responses $[4,5]$. It contributes also to the chronic inflammatory process [6]. In fact, high levels of IL-6 have been reported in several chronic inflammatory and autoimmune diseases as well as in cancer [7].

The main cellular sources of IL-6 are monocytes and T cells, but it can also be produced by other cells including epithelial cells [4].

IL-6 binds to its agonist receptor, which can exist in the transmembrane form (IL-6R or gp80) and in the soluble form (sIL-6R or gp50). This initial complex can then binds to the trans membrane protein gp130 to initiate intracellular signal transduction and gene expression [8].

The classical IL-6 signal is limited to cells (hepatocytes, macrophages, neutrophils, T cells, etc) that express IL-6R on their cell surface [9].

Cells do not expressing IL-6R, as stromal and epithelial cells, are able to respond to IL- 6 because the soluble form of the receptor binds to IL-6 and then anchors to membrane gp130 receptor, initiating a trans-signaling pathway. For this reason, sIL-6R is able to increase the function of IL- 6 and is considered the agonist form of its receptor.

When the level of IL- 6 increases, its effects are widely expressed because gp130 molecules are ubiquitous and, therefore, also present in cells without IL-6R in the membrane form.

On the contrary, a soluble form of the glycoprotein 130 (sgp130) can complex with sIL-6R to prevent the sIL-6R from binding to the membrane-bound gp130. In this case sgp130 is able to decrease the function of IL- 6 and is considered the antagonist form of IL-6 receptor system [10].

One of the main activators of IL-6 expression is Tumor Necrosis Factor- $\alpha$ (TNF- $\alpha$ ), a pleiotropic molecule that plays a central role in inflammation, immune system development and in a large number of pathological diseases.

Elevated IL-6 level is a hallmark inflammatory signature seen in serum of patients with severe COVID-19 acute respiratory distress (ARDS) [1].

As no specific anti-viral treatment exists, our confirmed COVID-19 patients were treated with steroids, in order to decrease inflammation, and with tocilizumab that specifically binds soluble and membranebound IL- 6 agonist receptors in order to inhibit IL- 6 signal transduction $[11,12]$.

The aim of this study was the analysis of a possible role of IL- 6 and its receptor complex and TNF- $\alpha$ in critically ill COVID-19 patients with ARDS, by monitoring cytokines blood levels during disease progression and evolution.

\section{Materials and methods}

\section{Patients}

During the period from March 10 to April 30, 2020, N=23 critically patients with confirmed COVID-19 were admitted in Intensive Care Unit (ICU) due to severe respiratory failure. The confirmed cases of COVID-19 was defined by a positive reverse-transcriptasepolymerase-chain-reaction (RT-PCR) assay of a specimen collected on a nasopharyngeal swab. The demographic and clinical characteristics of the patients are shown in Table 1 . The mean \pm S.D. age of the patients
Table 1. Characteristics of the patients

\begin{tabular}{|c|c|c|c|}
\hline & & $\mathrm{N}$ & $\%$ \\
\hline \multirow{2}{*}{ Gender } & M & 18 & $78,26 \%$ \\
\hline & $\mathrm{F}$ & 5 & $21,74 \%$ \\
\hline Hypertension & Yes & 18 & $78,26 \%$ \\
\hline Dyabetes & Yes & 9 & $39,13 \%$ \\
\hline Obesity & Yes & 7 & $30,43 \%$ \\
\hline Tocilizumab & Yes & 9 & $39,13 \%$ \\
\hline Steroids & Yes & 14 & $60,87 \%$ \\
\hline \multirow{2}{*}{ Mortality } & Dead & 12 & $52,17 \%$ \\
\hline & Alive & 11 & $47,83 \%$ \\
\hline
\end{tabular}

was $66,88 \pm 14,48$ years; $78,26 \%$ were men. Hypertension, diabetes and obesity were the main comorbidities. The mean time from the first positive swab to ICU admission was 5 days, while the length of ICU stay was 15 days.

This study was performed in the ICU of the University of Naples "Federico II"- Medical School - Italy. The local ethics committee (Azienda Ospedaliera Universitaria Policlinico "Federico II", Naples Ethic Committee, protocol number: 155/20) approved the investigative protocol, and written informed consent was obtained from each patient or next of kin.

All human study procedures were performed in accordance with the principles outlined by the Declaration of Helsinki [13].

\section{Methods}

At 08:00 a.m., a fasting venous blood sample was obtained, and serum IL-6, sIL-6R, sgp130 and TNF- $\alpha$ levels were measured.

IL-6 serum determination was performed by Chemiluminescent Immunoassay (CLIA) by IMMULITE 2000 (SIEMENS Healthcare Diagnostics, Italy); serum levels of sIL-6R, sgp130 and TNF- $a$ were determined using automated Enzyme-Linked Immuno Sorbent Assay (ELISA) by analyzer Triturus System (GRIFOLS, Italy); R\&D Quantikine ELISA Kits (R\&D Systems, Minneapolis, MN - DIACHEM s.r.l., Italy distribution) were employed for all determinations.

The intra-assay and inter-assay coefficients of variation were $<5 \%$ for IL- 6 and sgp130 serum levels, and $<10 \%$ for sIL-6R and TNF- $a$ evaluation, respectively.

Normal values were observed in 32 age- and sex-matched healthy control subjects (mean age 57,92 $\pm 9,14$ years; M:F 22:10) without a family history of COVID-19, who were recruited from employees of Azienda Ospedaliera Universitaria Policlinico "Federico II", Naples (Table 2).

\section{Statistical analysis}

Data are expressed as mean \pm S.D. Statistical evaluation of data, by InStat 3.0 software (GraphPad Software Inc., San Diego, California, USA), was performed by Mann-Whitney test. Two-sided P values less than 0.05 were considered significant.

\section{Results}

In order to understand the role of inflammatory "cytokine storm" in critically ill COVID-19 patients, the serum levels of IL- 6 and its soluble receptor complex and TNF- $\alpha$, were determined as the mean value of different monitoring determinations at different times in all patients and compared to the control values. 
Serum sgp130 levels are decreased in COVID-19 patients compared to the healthy group, as shown in Table 2 .

On the contrary, the levels of IL-6 and its agonist receptor sIL6R and TNF- $\alpha$ were significantly increased in the patients. In particular, the amount of IL- 6 in patients was about 400 times more than the healthy controls, the amount of sIL-6R was almost triple, and the amount of TNF- $\alpha$ was almost 5 times, as shown in Table 2.

Focusing our attention on the obtained results, we noticed that not all patients have higher values of sIL-6R, compared to the controls. Indeed there was a first group of patients $(43,5 \%)$ with normal levels of sIL-6R $(31,05 \pm 8,22)$ (GROUP 1).

On the contrary, another group of patients $(56,5 \%)$ showed sIL-6R very high values $(127,65 \pm 76,63)$ (GROUP 2), as shown in Figure 1.

For this reason, we have stratified all patients, based on these two different sub-groups, dividing the patients on GROUP 1 (sIL-6R normal values) and GROUP 2 (sIL-6R increased values).

As reported in Figure 2, we observed that in GROUP 1 the IL-6 levels are $76,58 \pm 162,68 \mathrm{pg} / \mathrm{ml}$, that is 42 fold more than the controls, and in GROUP 2 the IL-6 levels reached a value of 1076,54 $\pm 2364,27 \mathrm{pg} /$ $\mathrm{ml}$ (600 fold more than the controls) $(\mathrm{P}<.001)$.

On the contrast, in the two sub-groups of patients serum sgp130

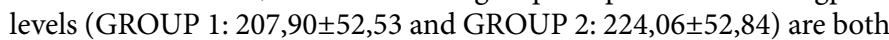
significantly decreased in respect to the controls $(\mathrm{P}<.001)$ (Figure 3$)$.

Always following this grouping, in Figure 4 is shown that TNF- $\alpha$ serum levels in GROUP 1 and GROUP 2 respectively are 23,25 $\pm 14,58$ $\mathrm{pg} / \mathrm{ml}$ and $57,03 \pm 72,16 \mathrm{pg} / \mathrm{ml}$ ( 3 and 7 fold more amount compared to the controls $)(\mathrm{P}<.001)$

Table 2. Levels of IL-6, sIL-6R, sgp130 and TNF- $\alpha$ in serum of controls and all times patients determinations (mean \pm S.D.)

\begin{tabular}{|c|c|c|}
\hline & Controls (mean \pm S.D.) & Patients $(m e a n \pm$ S.D. \\
\hline IL-6 $(\mathrm{pg} / \mathrm{ml})$ & $1,81 \pm 0,89$ & $702,99 \pm 1932,54$ \\
\hline sIL-6R $(\mathrm{ng} / \mathrm{ml})$ & $29,91 \pm 8,16$ & $90,42 \pm 74,29$ \\
\hline sgp130 $(\mathrm{ng} / \mathrm{ml})$ & $305,24 \pm 44,99$ & $217,92 \pm 53,14$ \\
\hline TNF- $\alpha(\mathrm{pg} / \mathrm{ml})$ & $8,51 \pm 0,54$ & $44,56 \pm 60,14$ \\
\hline
\end{tabular}

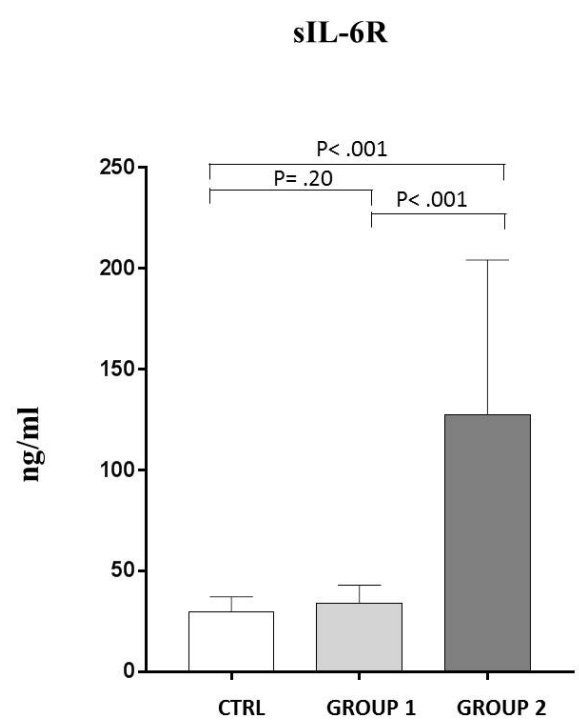

Figure 1. Analysis of sIL-6 R levels (ng/ml) behavior in patients studied (mean \pm S.D.) Group 1: $(31,05 \pm 8,22)$; Group 2: $(127,65 \pm 76,63)$; C: healthy controls $(29,91 \pm 8,16)$

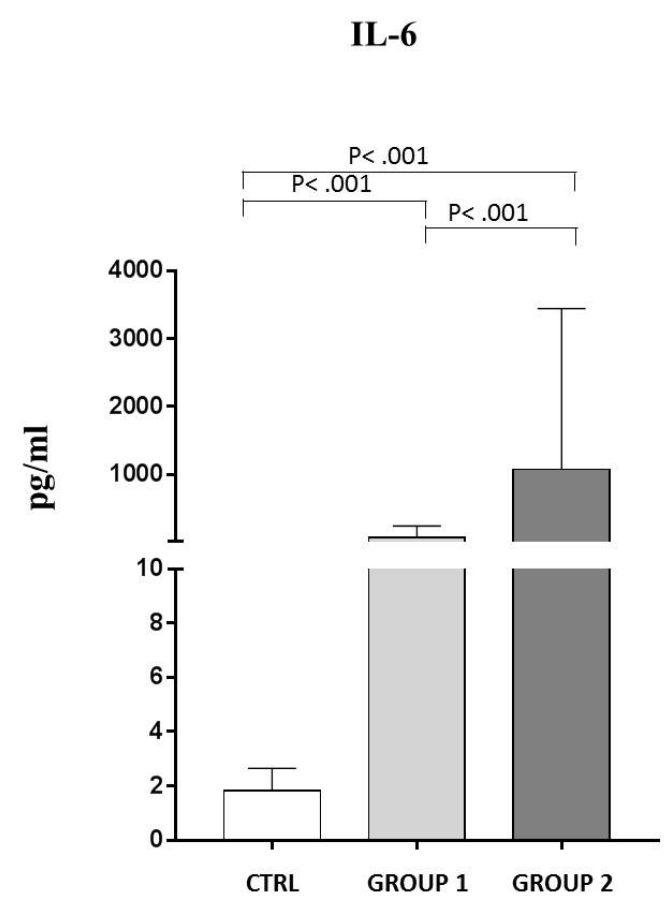

Figure 2. Analysis of IL-6 levels $(\mathrm{pg} / \mathrm{ml})$ in observed patients (mean \pm S.D.) Group 1: IL-6 levels (76,58 $\pm 162,68)$; Group 2: IL-6 levels (1076,54 $\pm 2364,27)$; C: healthy controls $(1,81 \pm 0,89)$

\section{$\operatorname{sgp} 130$}
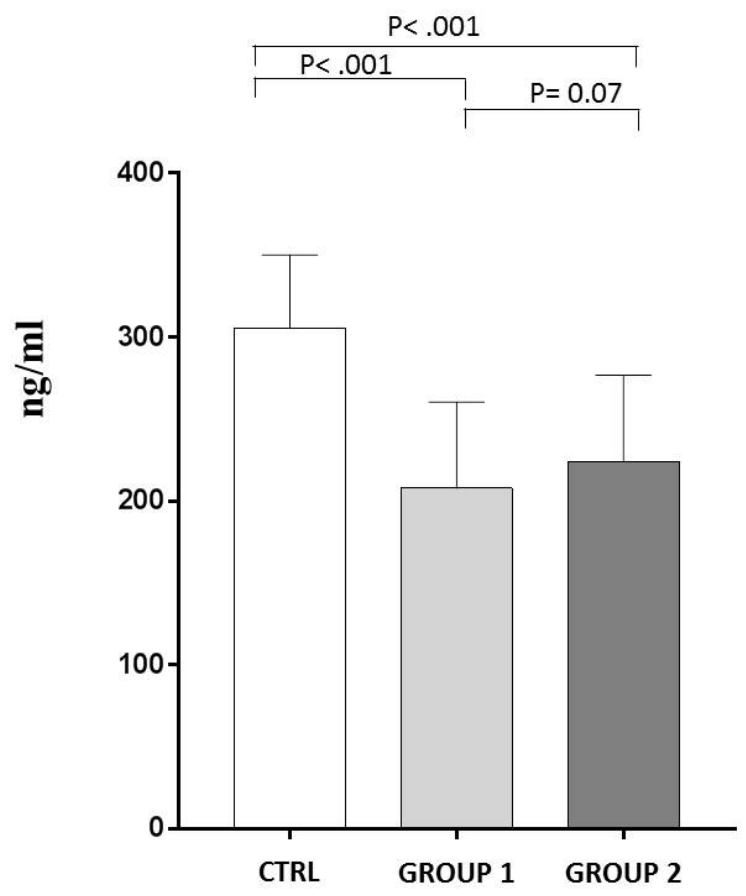

Figure 3. Analysis of sgp130 levels (ng/ml) in observed patients (mean \pm S.D.) Group 1: sgp 130 levels $(207,90 \pm 52,53)$; Group 2: sgp 130 levels $(224,06 \pm 52,84)$; C: healthy controls $(305,24 \pm 44,99)$ 


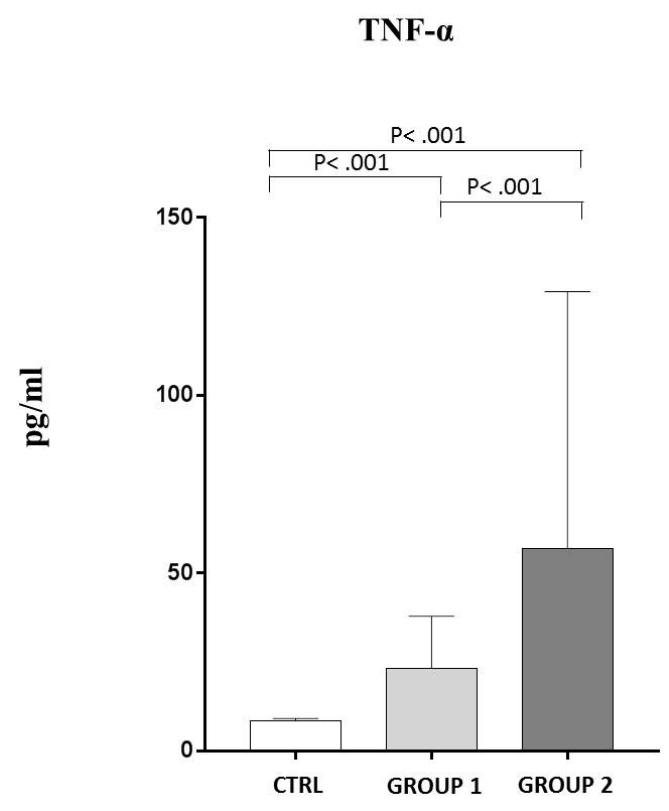

Figure 4. Analysis of TNF- $\alpha$ levels $(\mathrm{pg} / \mathrm{ml})$ in observed patients (mean \pm S.D.) Group 1: TNF- $\alpha$ levels $(23,25 \pm 14,58)$; Group 2: TNF- $\alpha$ levels $(57,03 \pm 72,16)$; C: healthy controls $(8,51 \pm 0,54)$

\section{Discussion and conclusions}

Our data show two different conditions in observed patients: a GROUP 1 with normal levels of sIL-6R, agonist soluble receptor for IL-6, and a GROUP 2 with very elevated levels of this marker. This condition modulates the expression of serum IL-6, that results dramatically elevated in the GROUP 2, that comprises a very critically ill patients with COVID-19.

The modulation of IL- 6 levels by sIL-6R serum concentration is further accentuated by the observation that levels of sgp130, antagonist soluble receptor, decrease in all patients. In this context, the IL-6 levels are higher and statistically different between the GROUP 1 and 2 . Therefore, increased IL-6 levels are substained by sIL-6R up-regulation, whereas sgp130 does not exert the antagonist modulation.

We could hypothesize that the lack of sgp130 increase could be the main player in IL-6 increase in those patients.

Also the TNF- $\alpha$, increased in both group of patients, plays a pivotal role in cytokines storm.

It is possible to hypothesize that this disregulation in blood inflammation mediators may contribute to a different prognosis and a different pharmacological response to tocilizumab and steroids. In fact, the progression of COVID-19 in the second week of illness is associated with the cytokine storm, which is thought to be responsible for the clinical exacerbate of many patients.

In particular, the results obtained in critically ill patients with COVID-19, where the cytokine storm is already begun, suggested that the steroids may be more effective than tocilizumab to control the inflammatory reaction (data not showed).

Further studies are required to better investigate the role of IL-6 and its soluble receptor complex during COVID-19 disease, and to evaluate the possible involvement of other cytokines as well as IL-17 and IL22 by Treg activation, also in response to different pharmacological treatment.
At this moment, we have started a supplementary study to verify if the cytokine expression due to the different polymorphisms in the IL-6 gene is involved in a possible mechanism of rapid disease progression COVID-19 as well as have demonstrated in different diseases [14-16] and to predict their poor prognosis.

\section{Acknowledgments}

We acknowledge Dr. Anna Diessa for technical and analytical contribution.

\section{Conflicts of Interest}

The authors declare no conflict of interest for this study.

\section{References}

1. Ascierto PA (2020) Insights from immuno-oncology: The Society for Immunotherapy of Cancer Statement on access to IL-6-targeting therapies for COVID-19. Journal for ImmunoTherapy of Cancer 8: e000878. [Crossref]

2. Baran P, Hansen S, Waetzig GH, MAkbarzadeh M, Lamertz L, et al. (2018) The balance of Interleukin (IL)-6, IL-6·soluble IL-6 receptor (sIL-6R), and IL-6·sIL-6R-sgp130 complexes allows simultaneous classic and trans-signaling. J Biol Chem 293: 67626775. [Crossref]

3. Ulhaq ZS, Soraya GV (2020) Interleukin-6 as a potential biomarker of COVID-19 progression. Med Mal Infect 50: 382-383. [Crossref]

4. Unver N, McAllister F (2018) IL-6 Family Cytokines: Key inflammatory mediators as biomarkers and potential therapeutic targets. Cytokine Growth Factor Rev 41: 10-17. [Crossref]

5. Spatuzza C, Postiglione L, Covelli B, Ricciardone M, Benvenuti, et al. (2014) Effects of berberine and red yeast on proinflammatory cytokines IL- 6 and TNF- $\alpha$ in periphera blood mononuclear cells (PBMCs) of human subjects. Front Pharmacol 5: 230. [Crossref]

6. Diaz-Torne C, Ortiz MA, Moya P, Hernandez MV, Reina D, et al.(2018) The combination of IL-6 and its soluble receptor is associated with the response of rheumatoid arthritis patients to tocilizumab. Seminars in Arthritis and Rheumatism 47: 757-764. [Crossref]

7. Tanaka T, Narazaki M, Kishimoto T (2014) IL-6 in Inflammation, Immunity, and Disease. Cold Spring Harb Perspect Biol 6: a016295 [Crossref]

8. McGonaglea D, Sharifa K, O'Regan A, Bridgewood C (2020) The Role of Cytokines including Interleukin-6 in COVID-19 induced Pneumonia and Macrophage Activation Syndrome-Like Disease. Autoimmunity Reviews 19: 102537. [Crossref]

9. Zhang C, Wu Z, Li JW, Zhao H, Wang GQ, (2020) Cytokine release syndrome in severe COVID-19: interleukin-6 receptor antagonist tocilizumab may be the key to reduce mortality. Int J Antimicrob Agents 55: 105954. [Crossref]

10. Rose-John S (2012) IL-6 Trans-Signaling via the Soluble IL-6 Receptor: Importance for the Pro-Inflammatory Activities of IL-6. Int J Biol Sci 8: 1237-1247. [Crossref]

11. Luo P, Liu Y, Qiu L, Liu X, Liu D, Li J (2020) Tocilizumab treatment in COVID-19: A single center experience. J Med Virol 2: 814-818. [Crossref]

12. Alattar R, Ibrahim TBH, Shaar SH, Abdalla S, Shukri K, et al. (2020) Tocilizumab for the treatment of severe coronavirus disease 2019. J Med Virol 4: 1-8. [Crossref]

13. Rickham, PP (1964) Human experimentations. Code of ethics of the World Medica Association. Declaration of Helsinki. Br Med J 2: 177. [Crossref]

14. Hu P, Chen Y, Pang J, Chen X, (2019) Association between IL-6 polymorphisms and sepsis. Innate Immun 25: 465-472. [Crossref]

15. Chen Y, Hu Y, Song Z (2019) The association between interleukin-6 gene -174G/C single nucleotide polymorphism and sepsis: an updated meta-analysis with tria sequential analysis. BMC Med Gen 20: 35 [Crossref]

16. Paradowska-Gorycka A, Roszak M, Stypinska B, Lutkowska A, Walczyk M, et al (2019) IL-6 and TGF- $\beta$ Gene Polymorphisms, Their serum levels, as well as HLA profile, in patients with Systemic Lupus Erythematosus. Clin Exp Rheumatol 37: 96397 [Crossref]

Copyright: (C2020 Di Spigna G. This is an open-access article distributed under the terms of the Creative Commons Attribution License, which permits unrestricted use, distribution, and reproduction in any medium, provided the original author and source are credited. 